\title{
TESTING BLENDED LEARNING IN THE HOME ECONOMICS NUTRITION MODULE
}

\author{
[PREVERJANJE OBRNJENEGA UCENJA PRI MODULU \\ PREHRANA]
}

\author{
Jana Beronja - Francka Lovsin Kozina
}

\section{doi: 10.18355/PG.2017.6.2.2}

\begin{abstract}
Technological development has changed the way of teaching. The aim of the present study which included 143 pupils of the $6^{\text {th }}$ grade of the nine-year elementary school was to determine whether the knowledge of pupils after the introduction of blended learning would be better than the knowledge of pupils who acquired knowledge through the frontal teaching method. The results showed that the knowledge of pupils in the blended class was better than the knowledge of pupils in the control group. Most pupils had a positive attitude to learning through modern ICT. Constantly accessible video recordings of the new content seemed appropriate to pupils in terms of better preparedness for new lessons, repetition of the new content in order to improve the assessment and the ability to follow the new content at their own pace.
\end{abstract}

Key words

home economics, blended learning, nutrition education

\section{Povzetek}

$\mathrm{S}$ tehnološkim razvojem se spreminja tudi način poučevanja. Z raziskavo, $\mathrm{v}$ katero je bilo vključenih 143 učencev 6. razreda devetletne osnovne šole, smo želeli ugotoviti, ali bo znanje učencev po uvedbi obrnjenega učenja boljše od znanja učencev, ki so ga pridobivali s klasično metodo poučevanja. Rezultati so pokazali, da je bilo znanje učencev, ki so se učili s pomočjo obrnjenega učenja, boljše od znanja učencev kontrolne skupine. Večina učencev tudi pozitivno sprejema možnost učenja s pomočjo IKT. Učencem se zdijo stalno dostopni videoposnetki nove snovi primerni $\mathrm{z}$ vidika boljše pripravljenosti na pouk, ponavljanja nove snovi z namenom izboljšanja ocene in možnosti sledenja novi snovi z lastnim tempom.

\section{Ključne besede}

gospodinjstvo, obrnjeno učenje, prehransko izobraževanje

\section{Uvod}

$\mathrm{V}$ literaturi zasledimo več poskusov definiranja obrnjenega učenja (Osghuthorpe \& Graham, 2003; Singh, 2003; Garison \& Kanuka 2004; Graham 2006). V osnovi vse definicije poudarjajo povezavo dveh prepletajočih se elementov - neposredne interakcije med učencem in učiteljem ter učenja $\mathrm{s}$ pomočjo sodobne informacijsko-komunikacijske 
tehnologije. Takšen pristop je pravzaprav nadgradnja prvotnemu podajanju informacij s pomočjo različnih informacijskih medijev, kot so elektronska pošta, radio, televizija, in poznejšega učenja na daljavo (distance learning), saj kombinira delo $\mathrm{v}$ razredu (face to face instructions) $\mathrm{z}$ možnostmi sodobne računalniške tehnologije (So \& Brush, 2007) in je tako imenovana »third generation of distance education « (Phipps \& Merisotis (1999, str. 26 v So \& Brush, 2007)). Obrnjeno učenje se v literaturi omenja v kontekstu na učenca osredotočenega učenja, za katerega je značilen poudarek na aktivnem učenju, učenju z razumevanjem, večji odgovornosti učenca, večjem občutku avtonomije učenca, soodvisnosti učitelja in učenca, vzajemnem spoštovanju in refleksiji (Lea et al, 2003, str. 322). Poleg številnih prednosti pa v literaturi zasledimo tudi pomanjkljivosti obrnjenega učenja (tabela 1).

\begin{tabular}{|c|c|}
\hline \multicolumn{2}{|r|}{ Prednosti } \\
\hline Osredotočenost na lastno učenje. & The Teacher's Guide To Flipped Classrooms, b.d \\
\hline Večja motiviranost. & The Teacher's Guide To Flipped Classrooms, b.d \\
\hline Hitra povratna informacija. & The Teacher's Guide To Flipped Classrooms, b.d \\
\hline Individualiziran pristop. & $\begin{array}{l}\text { The Teacher's Guide To Flipped Classrooms, b.d; } \\
\text { Bergmann in Sams, } 2014\end{array}$ \\
\hline $\begin{array}{l}\text { Lažje spremljanje učnega napredka } \\
\text { učencev. }\end{array}$ & $\begin{array}{l}\text { Marshall, 2013, v Hamdan, McKnight, McKnight, } \\
\text { Arfstrom (2013) }\end{array}$ \\
\hline $\begin{array}{l}\text { Učinkovita prilagoditev dela za osebe } \mathrm{s} \\
\text { posebnimi potrebami. }\end{array}$ & $\begin{array}{l}\text { Pierce (2015), Kavkler in ostali (2003), Ahčin in } \\
\text { ostali (2003) }\end{array}$ \\
\hline $\begin{array}{l}\text { Boljša organizacija dela doma (domače } \\
\text { naloge). }\end{array}$ & Bergmann in Sams (2014) \\
\hline $\begin{array}{l}\text { Starši lažje pomagajo svojemu otroku, } \\
\text { če je to potrebno. }\end{array}$ & Bergmann in Sams (2014) \\
\hline \multicolumn{2}{|c|}{ Pomanjkljivosti } \\
\hline $\begin{array}{l}\text { Učitelj lahko le posreduje } \\
\text { videoposnetke. } \\
\text { Učitelj ima veliko dodatnega dela. }\end{array}$ & $\begin{array}{l}\text { Bergman in Sams (2014) } \\
\text { Aronson in Arfstrom (2013) }\end{array}$ \\
\hline $\begin{array}{l}\text { Učitelj ima lahko pomanjkljivo znanje o } \\
\text { snemanju posnetka. }\end{array}$ & Sams, Bergmann (2013) \\
\hline $\begin{array}{l}\text { Ne ustreza vsem učiteljem in ne vsem } \\
\text { učencem. }\end{array}$ & Hamdan, McKnight, McKnight, Arfstrom (2013) \\
\hline Ni osebne interakcije. & Hamdan, McKnight, McKnight, Arfstrom (2013) \\
\hline $\begin{array}{l}\text { Pričakovano več truda s strani učencev, } \\
\text { pričakovano sprotno učenje. }\end{array}$ & Aronson in Arfstrom (2013) \\
\hline
\end{tabular}

Table 1: Prednosti in slabosti obrnjenega učenja

Glowain in Goodell (2016) navajata naslednja načela učenja, ki so osredotočena na učenca:

- Učenje je personalizirano.

- Učenje temelji na kompetencah.

- Učenje lahko poteka kadarkoli, kjerkoli.

- Učenci prevzamejo odgovornost za svoje učenje.

Vloga učitelja pri obrnjenem učenju se zelo spremeni. Učenec, ki si doma ogleda videoposnetek že pred učno uro, samostojno spozna dejstva. Primarna 
vloga učitelja pri pouku ni več podajanje nove snovi, čas pri učni uri pa se lahko porabi za odgovore na vprašanja učencev in za individualno pomoč učencem (Sams in Bergmann, 2013). Tako lahko pri pouku učitelj vpelje dejavnosti, s katerimi učenci dosežejo tudi višje taksonomske ravni znanja po Bloomu.

Učenje s pomočjo obrnjenega učenja zahteva temeljit razmislek na individualni in organizacijski ravni. Bergman in Sams (2014) navajata naslednje komponente obrnjenega učenja, na katere je treba biti pozoren pri zagotavljanju kakovostnega poučevanja s pomočjo obrnjenega učenja:

- $\quad$ sodelovanje: obrnjeno učenje težko vpelje učitelj sam, potrebna sta sodelovanje in izmenjava idej s kolegi;

- na učenca osredotočeno učenje: pri frontalnem pouku je učitelj posredovalec znanja, pri obrnjenem učenju pa se s tem, ko učitelj stopi v ozadje in postane povezovalec, ne več posredovalec znanja, center pozornosti preusmeri na učenca;

- $\quad$ optimizirani učni prostori: priporoča se preureditev prostora tako, da že sama postavitev omogoča način dela, ki poudarja aktivno učenje.

Posebno pozornost pri uvedbi obrnjenega učenja zahteva tudi izbira vsebine. $\mathrm{V}$ šestem razredu devetletne osnovne šole je mogoče o uvedbi obrnjenega učenja pri prehranskem izobraževanju razmišljati tako v okviru vsebin, ki so namenjene pridobivanju teoretičnega znanja, kot usvajanju praktičnih veščin. Ravno tako je treba učence ustrezno pripraviti na tak način dela. Guezer in Caner (2013) sta na podlagi analize štirih člankov, ki so obravnavali percepcijo obrnjenega učenja s strani učencev, ugotovila, da učenci kot bolj učinkovit način učenja sicer dojemajo učenje s pomočjo spleta, vendar si v učnem procesu želijo tudi osebne interakcije. V raziskavi, ki sta jo naredila Avdic in Åkerblom (2015), so učenci poudarili, da bi jim možnost, da predavanja le poslušajo, omogočila, da bi jih tako lahko poslušali ob delanju drugih dejavnosti (rekreacija ipd.).

\section{Problem}

Pri pouku gospodinjstva se obrnjeno učenje do izvedbe pedagoškega eksperimenta ni uporabljalo. Namen raziskave, ki je bila izvedena med 143 šestošolci, je bil pridobiti povratne informacije o sprejemljivosti tovrstnega učenja s strani učencev in učinkovitosti z vidika pridobivanja novega znanja. Raziskovalni vprašanji sta bili:

RV 1: V kateri skupini, kontrolni ali eksperimentalni, bo učni napredek po posameznih vprašanjih večji.

RV2: Kako učenci dojemajo vlogo videoposnetkov v procesu učenja z vidika pripravljenosti na pouk oziroma za njihovo učno uspešnost.

\section{Metoda dela}

Raziskava je bila izvedena med 143 učenci 6. razreda, ki so bili povprečno stari 11,3 leta. Za pedagoški eksperiment so bili učenci razdeljeni v dve skupini: eksperimentalno, $\mathrm{v}$ kateri je bilo uvedeno obrnjeno učenje, in kontrolno, v kateri je delo potekalo frontalno. Učenci eksperimentalne skupine so si doma ogledali videoposnetek nove učne snovi. Posnetek so dobili na šolski spletni strani, na kateri je bila povezava do videoposnetka na 
Youtubu, delo pri pouku pa je bilo namenjeno razreševanju vprašanj učencev in dejavnostim, ki so bile enake kot $\mathrm{v}$ kontrolni skupini po zaključku frontalne razlage. Učenci so se tako razdelili v skupine. Vsaka skupina je reševala drugačne naloge. Po določenem času so skupine zamenjale mesta (rotacija skupin), tako da so vsi učenci rešili vse predvidene naloge. Pri delu v skupinah so tako učenci iskali napake v besedilu, urejali nakupljena živila na ustrezna mesta in igrali spomin. $\mathrm{V}$ kontrolni in eksperimentalni skupini je bilo 14 dni po izvedbi pedagoškega eksperimenta izvedeno tudi preverjanje znanja s pomočjo spletnega kviza.

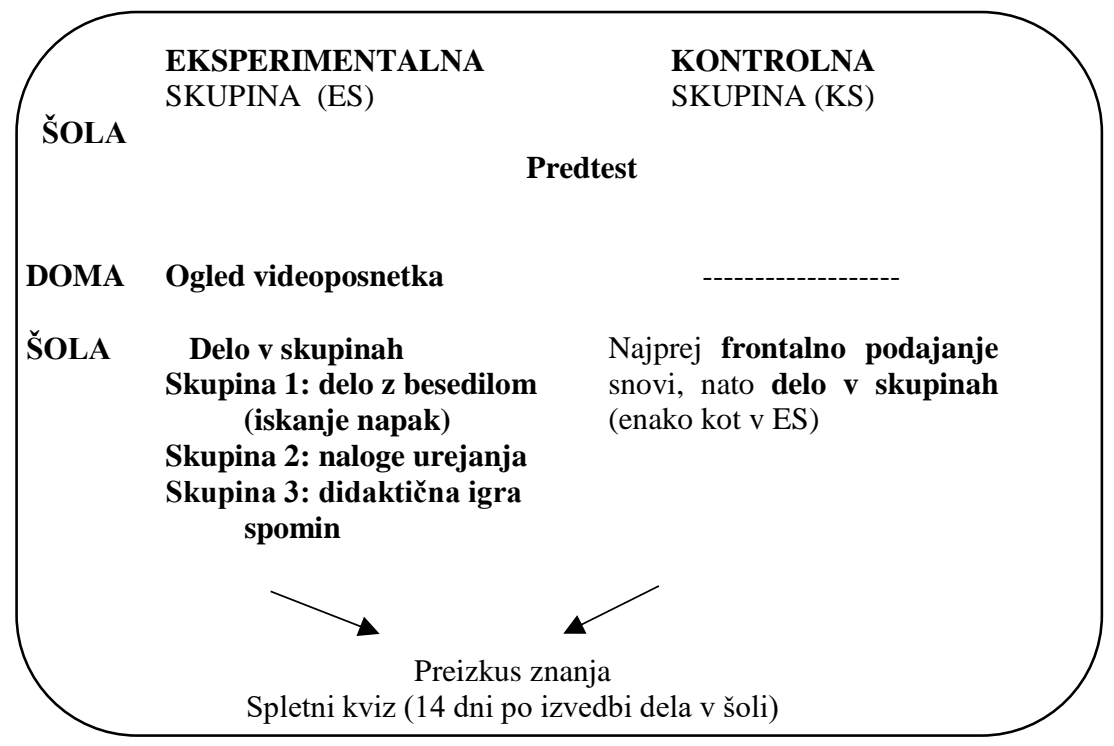

Slika 1: Zasnova pedagoškega eksperimenta

Kviz je bil oblikovan s pomočjo spletne strani EnKlikAnketa in je vseboval enake naloge kot pisni preizkus znanja (predtest). Uporabljena je bila deskriptivna statistika.

\section{Rezultati z diskusijo \\ Znanje}

Rezultati raziskave so pokazali, da je bil napredek v znanju, preverjan 14 dni po pedagoškem eksperimentu, pri 10 od 13 vprašanj večji v eksperimentalni skupini (slika 2). Analiza je tudi pokazala razliko v odstotku pravilnih odgovorov na vprašanja, ki so preverjala razumevanje konceptov. Pri osmih nalogah (1., 4., 5., 11., 12. a, 12. c, 13. b, 13. f), s katerimi je bilo preverjano razumevanje konceptov, je bila razlika med eksperimentalno in kontrolno skupino $15 \%$ in več. Dobljeni rezultat tako potrjuje ugotovitve Sams \& Bergman (2013), da pravilno zasnovano obrnjeno učenje lahko pripomore tudi k doseganju učnih ciljev višjih taksonomskih ravni po Bloomu. 


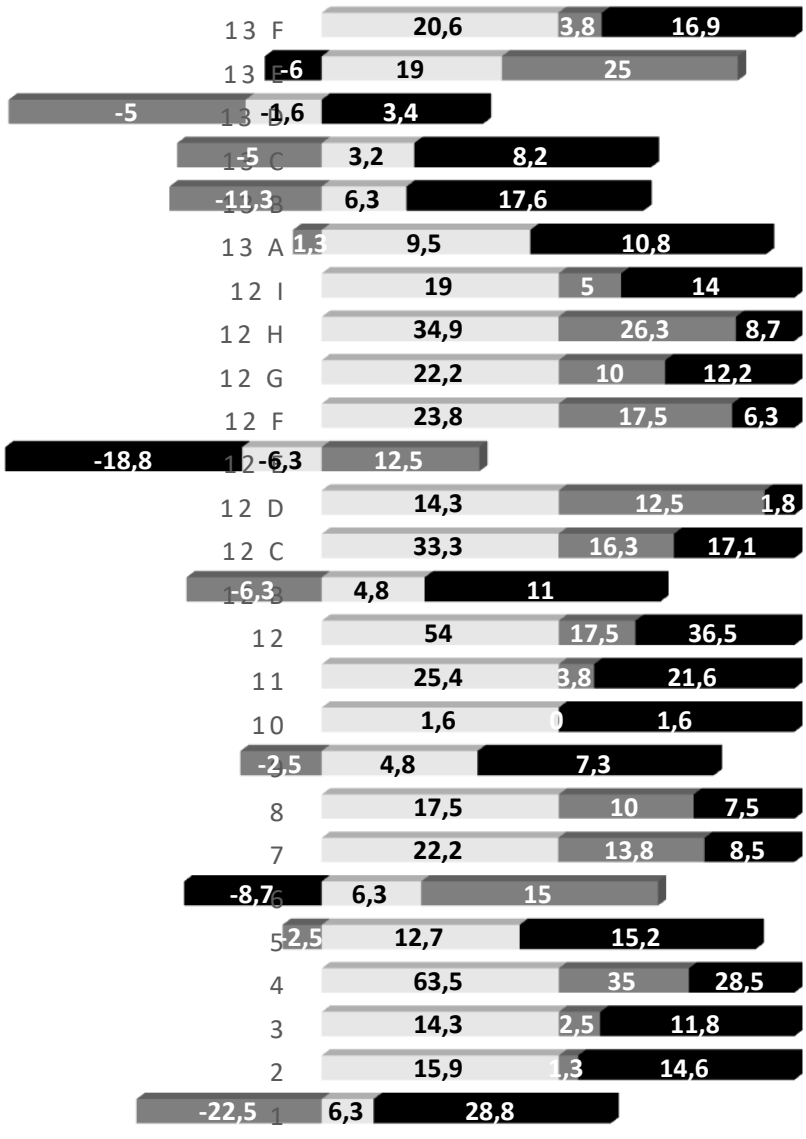

Eksperimentalna

Kontrolna

Razlika med

Slika 2: Primerjava razlik v deležu pravilnih odgovorov po 14 dneh glede na preverjanje predznanja za eksperimentalno in kontrolno skupino (v \%) po posameznih vprašanjih.

\section{Mnenje učencev o uporabnosti videoposnetkov v procesu učenja}

Rezultati so pokazali, da je večini anketiranih učencev učenje s pomočjo informacijsko-komunikacijske tehnologije všeč (70 \%). Približno polovica anketiranih učencev (52 \%) pa se je strinjala tudi s trditvijo »Učenje gospodinjstva tako, da bi si doma ogledal videoposnetek, mi je všeč.« Z navedeno trditvijo so se bolj močno strinjali učenci eksperimentalne skupine $(\mathrm{M}=3,9, \mathrm{SD}=0,84)$ kot učenci kontrolne skupine $(\mathrm{M}=3,4, \mathrm{SD}=1,13)$, kar bi lahko bila posledica izkušnje učencev eksperimentalne skupine $\mathrm{z}$ obrnjenim učenjem (Tabela 2). 


\begin{tabular}{|c|c|c|c|c|}
\hline \multirow[t]{2}{*}{ Trditev } & \multicolumn{2}{|c|}{$\mathrm{ES}(\mathrm{N}=63)$} & \multicolumn{2}{|c|}{$\mathrm{KS}(\mathrm{N}=80)$} \\
\hline & M & SD & M & SD \\
\hline $\begin{array}{l}\text { Učenje gospodinjstva tako, da bi si } \\
\text { doma ogledal videoposnetek, mi je } \\
\text { všeč. }\end{array}$ & 3,9 & 0,84 & 3,4 & 1,13 \\
\hline $\begin{array}{l}\text { Menim, da bi bil bolje pripravljen na } \\
\text { pouk gospodinjstva, če bi si doma } \\
\text { ogledal videoposnetek o obravnavani } \\
\text { snovi. }\end{array}$ & 3,8 & 1,19 & 3,5 & 0,94 \\
\hline $\begin{array}{l}\text { Če bi imel možnost, da si pred } \\
\text { preverjanjem znanja pri gospodinjstvu } \\
\text { spet ogledam videoposnetek z } \\
\text { obravnavano snovjo, da bi dobil boljšo } \\
\text { oceno, bi to storil. }\end{array}$ & 4,2 & 1,13 & 4,1 & 0,94 \\
\hline $\begin{array}{l}\text { Želel bi si, da bi imel na voljo več } \\
\text { videoposnetkov učne snovi pri pouku } \\
\text { gospodinjstva, saj bi si jih lahko } \\
\text { večkrat ogledal, če pri pouku česa ne bi } \\
\text { razumel. }\end{array}$ & 4,1 & 1,03 & 3,9 & 0,96 \\
\hline $\begin{array}{l}\text { Možnost, da videoposnetek ustaviš, } \\
\text { omogoča, da si težko snov večkrat } \\
\text { pogledaš in tako lažje slediš. }\end{array}$ & 4,1 & 1,13 & 4,1 & 0,87 \\
\hline
\end{tabular}

Table 2. Stališča učencev

214 S trditvijo: »Menim, da bi bil bolje pripravljen na pouk gospodinjstva, če bi si doma ogledal videoposnetek o obravnavani snovi« se je strinjalo 56,7\% učencev. $Z$ navedeno trditvijo so se nekoliko bolj strinjali učenci eksperimentalne skupine $(\mathrm{M}=3,8, \mathrm{SD}=1,19)$ kot učenci kontrolne skupine $(\mathrm{M}=3,5 ; \mathrm{SD}=0,94)$. Možnost, da si pred preverjanjem znanja pri gospodinjstvu spet ogleda videoposnetek z obravnavano snovjo, da bi dobil boljšo oceno, bi izkoristilo 742 , \% učencev. Tudi s to trditvijo so se nekoliko bolj strinjali učenci eksperimentalne skupine $(\mathrm{M}=4,2$; $\mathrm{SD}=1,13)$ kot učenci kontrolne skupine $(\mathrm{M}=4,7 ; \mathrm{SD}=0,94)$. 67,9\% učencev bi želelo, da bi imeli na voljo več videoposnetkov učne snovi pri pouku gospodinjstva, da bi si jih lahko večkrat ogledali, če česa ne bi razumeli. S to trditvijo so se bolj strinjali učenci eksperimentalne skupine $(\mathrm{M}=4,1 ; \mathrm{SD}=1,03)$ kot kontrolne skupine $(\mathrm{M}=3,9, \mathrm{SD}=0,96)$, vendar analiza ni pokazala statistično pomembnih razlik. S trditvijo: »Možnost, da videoposnetek ustaviš, omogoča, da si težko snov večkrat pogledaš in tako lažje slediš« se je strinjalo $79,1 \%$ učencev, pri čemer so se s to trditvijo enako močno strinjali učenci obeh skupin.

\section{Značilnosti dobrega videoposnetka - mnenje učencev}

Za dober videoposnetek je pomembno, da je primerno dolg, interaktiven, razdeljen na manjše sklope, ki jim sledijo povzetki (Raths, 2013). Z vidika učencev je dobro, da učitelj vsebino prosto predstavi (ne bere) oziroma da je videoposnetek pripravljen kot dialog, vključuje na primer demonstracije, predstavitev ppt in podobno (Sams \& Bergman, 2013). 
Zanimalo nas je, kateri elementi se zdijo učencem pomembni. Učenci so na to vprašanje odgovarjali prosto. $\mathrm{Na}$ podlagi vsebinske analize odgovorov so bili odgovori učencev smiselno združeni v naslednje skupine meril dobrega videoposnetka:

- na videoposnetku lahko nastopa sam učenec, njegovi sošolci ali učiteljica ter znane osebe,

- videoposnetek je smešen in zabaven,

- na videoposnetku je bila predstavljena aktivnost ali poskus,

- videoposnetek je animiran kot risanka ali pa v glavni vlogi nastopajo

živali,

- glasbena podlaga,

- interaktiven in bi vseboval računalniške igre,

- napisi, s katerimi se poudari pomembna vsebina,

- šport,

- uganke.

Dejstvo, da so učenci predlagali, da bi tudi sami sodelovali pri snemanju videoposnetkov, kaže na zanimanje učencev za uporabo IKT in obrnjenega učenja pri pouku.

\section{Sklepi in usmeritve}

Obrnjeno učenje, ki kombinira osebni pristop poučevanja in možnosti sodobne komunikacijske tehnologije, pomeni izziv pri poučevanju prehranskih vsebin tudi na osnovnošolski ravni. Takšen učni pristop se pri poučevanju v slovenskih osnovnih šolah še ne uporablja. Dejstvo je, da mladim danes IKT ni več tuja. Namen raziskave je bil tako preveriti sprejemljivost obrnjenega učenja z vidika učne uspešnosti in pridobiti mnenje učencev o tovrstnem načinu učenja. Rezultati so pokazali, da je večini učencev učenje s pomočjo IKT všeč. Uporabnost videoposnetkov, ki si jih lahko samostojno ogledajo doma, so prepoznali v možnosti, da se posnetek ustavi in spet zavrti v primeru nerazumevanja snovi, boljši pripravljenosti na pouk in možnosti za izboljšanje svojega znanja (pridobitvi boljše ocene). Rezultati so tudi pokazali, da so učenci, ki so se učili po načelu obrnjenega učenja, pri večini analiziranih vprašanj pokazali boljše znanje kot učenci, ki so $\mathrm{v}$ prvem koraku pridobivali znanje frontalno. $\mathrm{V}$ nadaljevanju bi bilo smiselno razmisliti o vsebinah, ki so kritične na področju prehranske pismenosti, in za njih pripraviti kakovostne videoposnetke. Posnetke bi si doma tako otroci večkrat ogledali sami ali pa skupaj s starši, ki bi lahko pridobili tudi strokovno ustrezne informacije (teoretične in smernice za praktično implementacijo naučenega pri načrtovanju in pripravi celodnevnega obroka). Ob tem pa je treba poudariti, da naj bo izbor vsebin, ki jih je smiselno obravnavati s preverjanim didaktičnim pristopom, prepuščen vsakemu učitelju $\mathrm{v}$ skladu $\mathrm{z}$ njegovo avtonomijo in usposobljenostjo za uporabo tega didaktičnega pristopa. Glede na dejstvo, da se obrnjeno učenje še ne uporablja pogosto na osnovnošolski ravni, bi bilo smiselno razmisliti tudi o uvedbi programov strokovnega izpopolnjevanja za učitelje, kjer bi pridobili morebitna manjkajoča tehnična znanja in ideje o implementaciji omenjenega didaktičnega pristopa v pouk. 


\section{Bibliographic references}

AHCIN, B. - MOREL BERA, I. - CUK, M. - FUCKA, Z. 2003. Navodila za delo $\mathrm{z}$ gibalno oviranimi ucenci. $\mathrm{V}$ Navodila za izobrazevalne programe $\mathrm{s}$ prilagojenim izvajanjem in dodatno strokovno pomocjo za devetletno osnovno solo, pp. 25-27.

ARONSON, N. - ARFSTROM, K. M. 2013. Flipped Learning in Higher Education. Pearson Always Learning.

AVDIC, A. - KERBLOM, L. 2015. Flipped classroom and learning strategies. In: Jefferies, A., Cubric, M., Barton, K. \& Lilley, M. (ed.), Proceedings of 14th European Conference on e-Learning (pp. 41-49). Reading, UK: Academic Conferences Publishing.

BERGMANN, J. - SAMS, A. 2014. Flipped Learning: Gateway to Student Engagement. United States of America: International Society for Technology in Education. Available online: https://books.google.si/books?hl=sl\&lr=\&id=r4OZCgAAQBAJ\&oi=fnd\&pg GLOWA, L. - GOODELL, J. 2016. Student-Centered Learning: Functional Requirements for Integrated Systems to Optimize Learning Vienna, VA.: International Association for K-12 Online Learning (iNACOL).

HAMDAN, N. - MCKNIGHT, E. P. - MCKNIGHT, K. - ARFSTROM, M. K. 2013. The Flipped Learning Model: A White Paper Based On The Literature Review Titled A Review Of Flipped Learning. Flipped Learning Network, 1-15.

GUZER, B. - CANER, H. 2014. The past, present and future of blended learning: an in depth analysis of literature. Procedia Social and Behavioral Sciences, 116(2014), pp 4596-4603.

GARRISON, D. R. - KANUKA, H. 2004. Blended learning: Uncovering its transformative potential in higher education. Internet and Higher Education, 7(2), pp. 95-105.

GRAHAM, C. R. 2006. Blended learning systems: Definitions, current trends and future directions. In C. J. Bonk. - C. R. Graham (Eds.), The Handbook of blended learning: Global perspectives, local designs (pp. 3-21). San Francisco: Pfeiffer.

KAVKLER, M. - MAGAJNA, L. - CACINOVIC, G. - PECJAK, S. KLUG, M. - VERNIK H. - BREGAR, K. 2003. Navodila za delo z ucenci s primanjkljaji na posameznih podrocjih ucenja. V Navodila za izobrazevalne programe $\mathrm{s}$ prilagojenim izvajanjem in dodatno strokovno pomocjo za devetletno osnovno solo, pp. 8-14.

LEA, S. J. - STEPHENSON, D. - TROY, J. 2003. Higher Education Students' Attitudes to Student Centred Learning: Beyond 'educational bulimia'. Studies in Higher Education 28(3), 321-334.

OSGUTHORPE, R. E. - GRAHAM, C. R. 2003. Blended learning environmens. Definitions and directions. The Quarterly Review of Distance Education, 4(3), pp. 227-233.

PHIPPS, R. - MERISOTIS, J. 1999. What's the difference? A review of contemporary research on the effectiveness of distance learning in higher education. Washington, DC: The Institute for Higher Education Policy. 
PIERCE, D. 2015. Flipped learning is changing the face of special ed. ESchool News Daily Tech News \& Innovation. Available online: www.eschoolnews.com/2015/06/29/flipped-special-ed-618/3/

RATHS, D. 2013.Video Tips for a Better Flipped Classroom. T.H. E. Journal pp. $12-18$.

SAMS, A. - BERGMANN, J. 2013. Flip Your Students' Learning. Educational Leadership, pp. 16-20.

SINGH, H. 2002. Building effective blended learning programs. Educational Technology, 43(6), 51-54.

THE TEACHER'S GUIDE TO FLIPPED CLASSROOMS. (B. D.). Available online: www.edudemic.com/guides/flipped-classrooms-guide.

SO, H., J. - BRUSH, T. A. 2007. Student perceptions of collaborative learning, social presence and satisfaction in a blended learning environment: Realationships and critical factors. Computer \&Education, 51 (2008), pp. 318-336. Doi: 10.1016/j.compedu.2007.05.009.

Jana Beronja

Pimary School Teacher - Home Economics teacher

Osnovna šola Šmihel, Šmihel 2, 8000 Novo mesto

Slovenia

beronja.jana@gmail.com

assoc. prof. dr. Francka Lovšin Kozina

Department of Home Economics

Faculty of Education

Kardeljeva ploščad 16, 1000 Ljubljana

Slovenia

Francka.lovsin@pef.uni-lj.si 